\title{
UMA BIBLIOTECA VIVA: A POESIA ARGENTINA CONTEMPORÂNEA
}

PORRÚA, Ana. Caligrafía Tonal. Ensayos sobre poesia. Buenos Aires: Entropía, 2011, 377 pp.

Quase todo livro, mais cedo ou mais tarde, tem a sua hora de entrar em uma biblioteca: na biblioteca do cânone, na biblioteca dos esquecidos, ou na infinita biblioteca dos que não têm biblioteca. Quase toda biblioteca precisa de um leitor que a defina como tal, que evidencie a sua existência para que, finalmente, outros leitores entrem nela e consigam colocar em questão a sua solidez. Ou seja, quase toda biblioteca, afinal de contas, tem o direito de que o leitor a transite por caminhos tortos, impensados, não canônicos. Quase toda biblioteca precisa que as suas estantes sejam um magma vivo, e não clorofórmicas classificações. Caligrafía tonal, de Ana Porrúa, testemunha, de uma forma tão plástica quanto exaustiva, os três movimentos: pega os livros, monta a biblioteca da poesia contemporânea argentina e nos convida a um percurso vivificante por entre os nomes mais significativos.

Ana Porrúa é argentina, professora da Universidad Nacional de Mar del Plata, pesquisadora do CONICET, editora da revista virtual Bazaramericano e poeta, e, desde os anos 1990, dedica sua reflexão à poesia contemporânea, principalmente argentina. Compilou duas antologias de poesia latinoamericana, publicou o ensaio Variaciones Vanguardistas. La poética de Leónidas Lamborghini (Beatriz Viterbo, 2001), prefaciou e antologizou a poesia de Arturo Carrera (Animaciones suspendidas, El otro el mismo, 2006), e publicou dezenas de artigos e resenhas sobre a poesia contemporânea argentina em importantes revistas culturais e publicações acadêmicas da Argentina e, inclusive, do Brasil.

Falar de poesia contemporânea solicita, no mínimo, alguns esclarecimentos, já que estamos frente a um termo - o de "contemporâneo" -, o qual, tal como acontece com as noções de "atual", “jovem" ou "novo" quando aplicadas a uma determinada produção literária, costuma ser associado a questões meramente cronológicas e, mesmo assim, vagas. Falamos de poesia contemporânea, por um lado, pela sua especificidade temporal: Porrúa costuma abordar a poesia que apareceu nas últimas décadas, sempre estabelecendo relações com as produções de outros tempos. Ou seja, a produção poética trabalhada em Caligrafia tonal seria contemporânea, num sentido corriqueiro, porque é feita nos últimos vinte anos. Mas também é contemporânea porque se trata de produções poéticas do mesmo tempo da crítica, do próprio tempo, (do meu tempo, diria Porrúa), 
estabelecendo uma situação complexa de simultaneidade, pertencimento e distância, que deixa entrever uma temporalidade heterogênea e nos aproxima das reflexões de Giorgio Agamben em O que é o contemporâneo (Argos, 2009). Se o poeta enquanto contemporâneo encara a fratura do seu próprio presente como algo obscuro, é porque procura um modo de pensar seu próprio tempo como impróprio, modo esse do qual a crítica pode e deve ser partícipe: "Aqueles que procuraram pensar a contemporaneidade puderam fazê-lo apenas com a condição de cindi-la em mais tempos". Desse modo, Caligrafia tonal pode ser definida como uma leitura contemporânea de uma poesia contemporânea, uma leitura e uma poesia que mantêm uma relação complexa consigo mesmas.

No entanto, não se trata apenas do interesse que suscita a sofisticação e complexidade do ponto de vista crítico. Caligrafía tonal constitui uma importante apresentação da poesia argentina das últimas décadas, praticamente desconhecida fora do âmbito argentino, e dos temas que definiram os debates em torno dela, ao longo das últimas décadas; apresentação que toma como fio condutor uma indagação sobre as “formas" dessa poesia.

Assim, o livro se inicia com um primeiro capítulo onde se colocam na mesa os alicerces teóricos que guiaram as leituras, a noção de "forma" de que ela se utiliza. A "forma" que Porrúa persegue, mesmo retornando às teorias dos formalistas russos ("para mostrar de ellas lo que abren (y no lo que se repite como reconstrucción de un sistema", p.15), nunca se trata de uma forma monumental, é muito mais um detalhe, uma fulguração dos materiais dispostos no livro ou no poema. Diz a autora em uma entrevista: "A mí me interesa leer la forma, el modo en que está escrito un poema, pero no como muestrario de recursos retóricos sino como movimiento del lenguaje y la cultura.". Essa "forma" instável como um traço é o que ela chama caligrafia e que lhe permite, atravessando diversas temporalidades, observar a biblioteca da poesia contemporânea nos seus encontros - harmônicos ou faiscantes - com poesias de outros tempos e outros lugares, principalmente, com o modernismo latino-americano de Leopoldo Lugones, Ruben Darío, a vanguarda martinfierrista e a inovação de Trilce de César Vallejo, mas também o barroco reformulado de Lezama Lima, ou de Nestor Perlongher.

O segundo e o terceiro capítulos são dedicados a um dos movimentos mais significativos e controvertidos das décadas de 80 e 90 da poesia argentina, aquele conhecido como "objetivista”. O grupo que se nucleava no conhecido Diário de PoesiaOsvaldo Aguirre, Daniel García Helder, Martín Prieto, Jorge Aulicino - entra em 
destaque tanto pela própria produção poética quanto pelas suas leituras e publicações de Ezra Pound. Nestes capítulos, evidenciam-se também as diferentes nuances do conflito da percepção, a aporia da sua imediaticidade, suas falhas, problemas que estão na base da própria nomeação desta corrente como "objetivista” e do seu esgotamento. A partir daí, além do núcleo forte do objetivismo, Porrúa vai abordar a produção de Martín Gambarotta, Laura Wittner e Fabián Casas, cujas poéticas são consideradas variações da primeira ou neo-objetivistas.

O quarto capítulo encena um gesto arriscado e necessário: ler a poesia contemporânea através da sua "colocação em voz", la puesta en voz, ou seja, através de leituras em voz alta, performances vocais e corporais. O capítulo instala o embate entre a leitura silenciosa, e a poesia para ser lida, e a presença de uma leitura/voz virtual que triangula a compreensão de um texto e abre novos significados pelo desdobramento de tons. Aqui se destaca a bela análise de Porrúa do Poesía espectacular film, filme de uma performance de leitura de diversas poesias onde Daniel Garcia Helder, Martín Prieto e Oscar Taborda, a partir da encenação e da declamação, colocam em tensão a poesia que leem, suas influências, e a própria poesia. A poesia e a sua forma, desse modo, são flagradas na zona onde fogem do especificamente textual.

O quinto capítulo apresenta diversos livros de poesia dos últimos anos, que não formam parte de uma corrente definida. Talvez seja este o capítulo de mais interesse para quem inicia um mergulho na poesia argentina atual e com menos bibliografia crítica disponível, já que - com a perícia de uma resenhista experiente e atenta para além dos desejos do mercado de poesia - Porrúa aborda, entre outros, o trabalho de José Villa, Roberta Iannamico, Juan Desiderio, Martín Gambarotta, nomes incontornáveis. Ou seja, o gesto ousado não está na escolha desses nomes, mas na evidenciação de que eles já se tornaram necessários para uma crítica da poesia contemporânea argentina.

Mas poderíamos arriscar que o espírito do livro, e da pesquisa de Porrúa como um todo, se encontra no sexto capítulo "Antologias". O capítulo se inicia com o primeiro trecho do conhecido ensaio de Walter Benjamin onde se lê: "estou desempacotando a minha biblioteca. Sim, estou. Os livros, portanto, ainda não estão nas estantes; o suave tédio da ordem ainda não os envolve" (in Rua de mão única. São Paulo, Brasiliense, 1987, p.227). De fato, o que vem a seguir se afasta da ordem de uma biblioteca tradicional. Porrúa apresenta algumas antologias da década de 90 e 00, justamente a partir das forças que as atravessam no momento mesmo da sua construção, no gesto do corte, nos critérios do corte, porque ali se produz a escrita do antologista: o corte é um gesto de 
intervenção claro em um campo em formação. Diz Porrúa: "Historia de la literatura, museo y canon son términos que suponen procesos temporales de larga o mediana duración y aquí se trata de antologías del presente (de caligrafías de época), de textos que aún no han ingresado en esos circuitos de legitimación” (p.259-260). E que, pelo fato de não serem textos canônicos, desde a sua aparição se tornam objetos da tradicional disputa crítica que paira sobre toda nova produção. A história da arte moderna, ou melhor, da sua recepção, mostra que geralmente as críticas feitas no calor da hora sendo as resenhas o pontapé do debate - se caracterizam, muitas vezes, tal como aponta Marcos Siscar em Poesia e crise (São Paulo, UNICAMP, 2010), pela insistência na declaração de óbito da poesia, da literatura ou da arte. A corriqueira afirmação de que a poesia está morta se alicerça na comparação dos descabimentos das produções impensadas com outras de um passado mais ou menos próximo, mas já canônica e para qual a crítica já dedicou páginas e páginas de exegese. Em compensação, outros críticos e os próprios autores assumem a defesa da vitalidade da poesia, da valorização da proposta, mesmo tendo que abrir mão de uma ideia moderna de qualidade; defesa que por vezes - talvez por ser reativa à reação conservadora - se torna superficial, mercadológica ou impressionista. Entre esses dois grandes fogos, estão algumas leituras que tentam se dar como escutas sensíveis sem perder o rigor.

Ao longo do capítulo sobre antologias observamos como foram se tecendo algumas das discussões sobre o campo da poesia argentina contemporânea em formação. Pelo fato de se tratar de antologias, umas em papel e outras virtuais, umas explicitamente temáticas, outras pretensamente objetivas, Porrúa nos mostra a complexidade do processo de consagração de uma poesia, de uma literatura, e as relações de poder e de afeto que dão forma ao campo. Campo cujos integrantes são os escritores, os editores e também a crítica, a crítica em geral e a crítica Ana Porrúa, a crítica afetiva. As disputas entre o que se chamou ora de poesia ruim, ora de cualquer coisa, como no instigante ensaio "Poesía actual e cualquierización", de Damián Selci e Ana Mazzoni. Mas o fato é que, na segunda metade da primeira década deste terceiro milênio, já é possível identificar certo consenso em relação à altíssima qualidade de grande parte dos poetas ativos e jovens. Tal como o atesta o sucesso entre os críticos e as reedições de, por exemplo, os autores nucleados em torno da editora VOX, de Bahía Blanca.

Nesse sentido, o capítulo re-encena os dois gestos implicados no ensaio de Benjamin: para ter uma biblioteca desordenada e livre das suas amarras, a única condição obrigatória é que ela já tenha sido ordenada e amarrada. Por isso, é neste capítulo que, 
lendo a contrapelo, se pode observar a desconstrução de uma biblioteca e o seu negativo construtivo. Se as antologias e os textos sobre elas atestam o calor do debate, a importância do corte eletivo e o movimento magmático da formação, o livro de Porrúa como um todo atesta o consenso e a estabilização desse campo: temos, finalmente e para começar, uma biblioteca, com todas as suas tramas de consagração.

Tal como nos informa ao final do livro, os textos ali presentes têm a sua origem em seminários, palestras, resenhas ou textos para revistas especializadas em poesia. Textos soltos e menores, textos que se dedicavam a pensar a poesia contemporânea argentina no calor da hora da sua produção. Caligrafía tonal não foge da vontade que guia, tal como o declara a própria autora, a sua produção de textos para revistas e constitui seu horizonte de pesquisa: entender em um só movimento "o que se escreve e como se lê". Mas a edição do livro imprime a esse afã pelo atual $e$ contemporâneo um tom particular. Nesse sentido, entre os artigos que lhe deram origem e a publicação de Caligrafía tonal há algumas diferenças substanciais, não tanto pela reescrita desses textos, mas pela distância cronológica - breve, mas significativa - e pela diferença da magnitude e solidez do seu suporte. Uma diferença substancial só percebida se levarmos em conta, tal como aponta Derrida em "Assinatura acontecimento contexto", não tanto a letra, mas a sua relação com aquilo que está ao seu redor. Se, na primeira escrita dos textos, a existência da poesia contemporânea argentina era o que estava em questão, nesta segunda aparição, essa existência é um pano de fundo indiscutível.

Caligrafía Tonal vem para evidenciar que a disputa da poesia da última década do século XX e a primeira do século XXI precisa mudar de tom: já não se trata de dizer se é ou não é poesia, se é boa ou má literatura, se é uma biblioteca ou uma coisa qualquer. Caligrafía tonal nos põe diante de uma biblioteca incontornável, inquestionável; e, para que o leitor a penetre e desconstrua os mitos do presente, deve entrar munido de outras bibliotecas, de outras leituras, inclusive teóricas. Boa parte da crítica de poesia brasileira contemporânea ainda deve fazer esse exercício e, em lugar de continuar declarando que a poesia está cada vez pior ou catatônica ou morta, possa ler as potências e as impotências que a poesia contemporânea brasileira deixa ver, com tudo de bom e de ruim que existe no fato de estar vivo. 